\title{
MARKETING STRATEGIES FOR PERISHABLE FRUITS AND VEGETABLES RETAIL SEGMENT IN SUPERMARKET
}

\author{
* Dr. Anitha Ramachander \\ ** S. Prasanna Venkatesh
}

\begin{abstract}
The recovery in consumer spending is visible across almost all the industry sectors especially in food and grocery. Revival and growth of Indian retail industry in the past few months are due to the early festive season. But at the same time, spending will not be as high as the previous years. Consumer's mentality and sentiment has changed as affected by the global situation. Now consumers are adopting a mindset of "Shift to thrift" approach. Consumers are focusing more on value from the offerings, whereby they want to save money everywhere and hence are seeking lower priced, acceptable quality options around food and grocery and other important purchases. Considering the recent economic and market changes, it is mandatory for the retailers to revisit on their value and marketing strategies to map the customer's new mindset and their spending habits. Keeping the above consideration, this study seeks to find out the supermarket's value delivery in terms of price, proximity or location, atmospherics, merchandise mix, customer service and differentiation in offerings etc. Based on these analysis, business models for supermarket were proposed to match the consumer's new mindset and preference.
\end{abstract}

Key words: Value proposition, fruits and vegetables retail, modern supermarkets

\subsection{Background of the study}

Falling stock indices, declining housing prices, growing inflation and global crisis made the Indian consumer's confidence index decline by 26.5 points between January 2008 to march 2009. But the market status is gradually improving, according to report titled "Indian consumers in the downturn" by Boston consulting group, worst is over for the retailers and industry, whose market size has been increasing and is likely to witness slow and steady growth. The recovery in consumer spending is visible across almost all the industry sectors especially in food and grocery. Revival and Growth of Indian retail industry in the past few months are due to the early festive season of the year and changing consumer demographics and an improvement in the quality of life of urban people. Consumer spending seems to be promising for next three quarters. But at the same time, spending will not be as high as the previous years. Consumer's mentality and sentiment has changed as affected by the global situation. Now consumers are adopting a mindset of "Shift to thrift" approach. Consumers are focusing

* Director, Adarsh Institute of Management \& Information Technology, Bangalore

Email : anithar72@yahoo.com

* Assistant Professor, Indian Business Academy, Bangalore

Email: spv.mktg@gmail.com 
more on value from the offerings, whereby they want to save money everywhere and hence are seeking lower priced, acceptable quality options around food and grocery and other important purchases.

Considering the recent economic and market changes, it is mandatory for the retailers to revisit on their value and marketing strategies to map the customer's new mindset and their spending habits. There are laggards who have not tuned their retail business according to the changing trends will lose business, recent slowdown of south Indian based supermarket and convenience store (subiksha) is the classical example. Another nationwide major supermarket chain store forced to shut down many outlets due to the lack of support network.

Leanings of the recent past made the Indian supermarket business to revisit on their value proposition and business model. Supermarket format is more risky proposition facing huge competition from local grocer especially in perishable fruits and vegetables segment. Hence it is need of the hour for modern supermarket to realign their marketing strategy in perishable goods. Keeping the above challenges in mind this study is an attempt to find out the realign strategies of supermarket in Bangalore city.

All these modern outlets (irrespective of the formats) are providing quality merchandise in packed foods, non food items and other groceries of either standard brands or their own private labels. But still, the consumers are dependent on mobile vendors or nearby vegetable market for fresh vegetables and fruits. Not many players are able to succeed and add value to this micro segment of fresh fruits and vegetables in terms of freshness, merchandise quality, pricing etc. Only a few players attempted to concentrate on fresh fruits and vegetables (F\&V). One of the major challenges of these players is a lack of skill in well - oiled system of replenishment or back-ward integration. Due to this reason, these players are having a hard time in delivering consistent value. Keeping the above challenges in mind, this study is an attempt to find out the value proposition of modern retail outlets in food and grocery sector especially in the fresh fruits and vegetables segment. This study seeks to find out the supermarket's value delivery in terms of price, proximity or location, atmospherics, merchandise mix, customer service and differentiation in offerings etc. There are various studies conducted on different formats and their deliverables, but there is little literature available on analyzing the realign strategies and business model of retailers towards this micro segment. This study is an attempt to find out the value delivery by these modern retail outlets especially in fruits and vegetables segment.

\subsection{Review of Literature}

\subsection{Literature review}

Various studies have been conducted on the growth of modern retail formats in India. Few of these studies are relate to food and grocery retail formats. In a study by Coca Cola retailing research council Asia (CCRA) on food retail format success in Asia, it was evident that food retailers were adding more value through innovative formats. Three modern food retail formats begin to emerge as the primary formats across the region: hypermarkets, supermarkets and convenience stores. Although supermarkets have become well entrenched on the Asian landscape (being the first modern retail format to enter most markets), convenience stores and hypermarkets have been leading the outlet expansion race in recent years, and hypermarkets have even become the most significant format in some markets. Especially in India, most of these formats are a new experience for shoppers. Their annual spending on modern food retail formats are considerably low compared to other markets in Asia. Indian shoppers are highly price sensitive in food shopping, therefore a format with wider choice and low prices will attract shoppers in this region. A study on growth of retail formats by 
Prof. Piyush Kumar Sinha clearly reiterates that retail format is the vehicle for delivering value preposition and positioning the concept of the stores in the minds of customers. The author further argues that retail formats is not only about physical structure, but to provide value added service and make customers feel worth of the value.

In a study on format choices of food and grocery retailers, it was found that format choice is an important decision making by the consumers as part of the information processing of his buying process. A store is chosen based on the confidence that the customer has regarding the store; about the nature and quality of product and service he will receive. In the Indian scenario formats have been found to be influencing the choice of store as well as orientation of the shoppers (Sinha and Uniyal, 2005). The same study seeks to analyze the various factors influencing decision making process of customers in choosing a store format. The exploratory study brought out five different formats that existed in the food and grocery sector. With this it also identified combinations of the seven parameters which have given rise to some generic retail formats. It also helped identifying the important factors which affect consumer format choice decisions. The findings also provide details which helps the retailers in designing an efficient retail package for offering to their customers.

Another research study by IFPRI, focused on the emergence of modern retailing with respect to food and its implications on various stakeholders in the food supply chain. While the study briefly further reviewed the US and European experience and focused on the developing countries of Latin America and East Asia (including China), where the supermarket revolution started in the early to mid-1990s. The study looked at the patterns of the diffusion process in modern retailing in terms of "waves" that go from country to country, and within a country from first-tier cities to second-tier and then a country from first-tier cities to second-tier and then third-tier cities, and from processed to semi processed to fresh products. The study also dealt with the challenges and opportunities that modern retailing was posed with various stakeholders in the supply chains, especially for traditional retailers, farmers, and consumers. The paper concludes by surmising what lessons other countries' experiences in the supermarket revolution have for India which is on the threshold of a major structural change in retailing. The expectations and concerns are high. Accordingly, India must form its own model of retail development to meet its priorities, learn from challenges that others have faced, and successful examples of strategies for "competitiveness with inclusiveness" among traditional retailers, wholesaler, and farmers entering an era of rapid retail transformation and concomitant food system change. (International food policy and research institute (IFPRI), February 2008)

Many of the above studies focus mainly on the store choice format and consumer preference in the food and grocery retail segment. Some of the above studies elaborated on the success of supermarket formats in India and suggested some alternative customized format to cater to the local needs. But none of the studies concentrated on the entire business model and realigning strategies of current modern retail specifically on the fruits and vegetables. Very few studies are available on consumer's perception on modern retail formats, and almost hardly any literature is available on analysing the strategy and business model of supermarkets in fruits and vegetables segment. Therefore this study is an attempt to find out the emerging and realigning strategies of modern retail format in food and grocery especially fruits and vegetables segment. 


\subsection{Research Methodology}

\subsection{Statement of the problem and need of the study}

Food and grocery retail segment constitute more than $60 \%$ of the overall retail industry. Many Modern retail formats in the above segment are providing different value proposition to cater to the needs of today's consumer. Still it was observed that many of these consumers prefer to purchase their fruits and vegetables from mobile vendors or nearby kirana stores. Reasons for the above preferences can be due to the following:

- Modern retailer's value delivery in this segment is not matching the changing mindset of the today's global recession economy.

- Value delivery is facing limitations in terms of skills in back-end operations and other infrastructural bottlenecks.

- Consumer's perception towards "value" in this Fruits and vegetable segment is distinct from other commodity and value purchases.

- Business model or formats of western countries is not matching the Indian consumer's food habits in the fruits and vegetables.

Modern formats of fruits and vegetables and their retail business model need to be realigned to cater to the local needs of Indian consumers. For this purpose, their value proposition should be revisited to match the value perception and expectation.

\subsection{Objective of this study}

The primary objective of this study is to find out the emerging strategies of Modern retail formats in the segment of food and grocery (especially fruits and vegetables section) from the retailer perspective.

The secondary objective of this study is as follows:

- To identify the modern supermarkets and their deliverables in Fruits and vegetable retailing.

- To analyze the suitable customized format for this fruits and vegetables segment in India.
- To suggest better strategies in terms of value chain network in this micro segment.

- To map the business model according to the new age customers.

\subsection{Methodology}

The present study is conducted at Bangalore city, the capital of Karnataka. The reason being, Bangalore enjoys the distinction of being one of the fastest growing metropolises across the globe. Over the past decade, the garden city has recorded a growth rate of close to 30 per cent in its population. It ranks seventh amongst other Indian cities in terms of 'affluent' population. More than one-third of the households in Bangalore have an annual expenditure between Rs 50,000 and Rs 1,00,000, and a majority of residents fall in the age bracket of 15-45 years, the ideal target market for a new generation retailer. Bangalore has been a leader in supermarkets, which were made popular by the RPG Group's Food World outlets. Currently 17 in number, the chain is still expanding into residential pockets of the city. Food World was initially responsible for making the concept of grocery store chains popular in Bangalore. Several others that have followed suit include More and Monday 2 Sunday Stores, Reliance fresh, Heritage group Fresh @ location etc. Hypermarkets also started gaining more prominence in Bangalore as consumers start patronizing the stores for their one stop value shopping. Majority of these modern retail outlets located in and around Jayanagar, southern part of Bangalore. Jayanagar is well developed residential area with cosmopolitan setup. There are theaters, shopping complexes, libraries and renowned educational institutions located here. Jayanagar shopping complex is the best place to shop at. This place also has some of the famous eating joints of Bangalore. Since Jayanagar is a major hub of shopping in Bangalore, this study is conducted at Jayanagar area. 


\subsection{Research Design}

Emerging marketing strategy was identified using certain common parameters relevant to supermarket. Value delivery was captured using the three broad variables namely Store convenience, choice and service; secondly, the value delivery of Modern retail formats was mapped using the common variables like Retail business model and value chain network etc. To explore further on value proposition common variables like price, proximity, merchandise mix, store atmosphere, customer service and differentiation strategies were considered for study purpose. Supermarket format were selected for the study purpose.

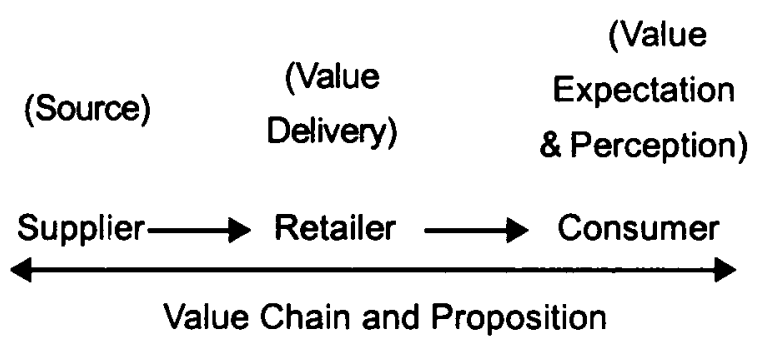

\subsection{Data collection}

\subsubsection{Primary Data}

Primary and secondary data were used for the study. Primary data related to retailer's store atmosphere, merchandise mix, customer service are collected by observation method.

\subsubsection{Secondary Data}

Secondary data are collected from different sources regarding the retail business model, value chain network etc. Major variables considered for analyzing the retail business model are Location, Merchandise mix (range, assortment and variety etc), price and service level. In value chain network, the organization's sourcing strategy, transportation network, storage and replenishment and lead time are considered. Secondary data collected from sources like industry reports, Company websites, corporate profiles, trade and business magazine and online databases like CMIE etc. These secondary data were analyzed qualitatively and the results were interpreted.

\subsection{Analysis of Data}

\subsection{Analysis Framework}

Presence of IT Professional and influx of migrant population made the Bangalore retail market as most attractive destination in the country. Last few years, the retail expansion in the city was on an accelerated pace with the entry of many organized corporate players in the form of supermarkets and hypermarkets. Since the late 2007 and 2008, Bangalore market has reached the saturation level where city is witnessing the trend of major retail activity being relocated from Central business district like M.G.Road, Commercial Street to peripheral locations like north Bangalore along with international airport route, Marrathalli ring road, Jayanagar, J.P.Nagar, Malleswarem and Rajajinagar etc. Jayanagar in south Bangalore is one of hot retail place where many retail activities is happening to cater to the large residential pockets of south Bangalore. To support their daily cores, many retailers set up their convenience stores and supermarket format to cater to the need of food and non food FMCG products. But still majority of the population are dependent on nearby vegetable mandi and push cart vendors for their green vegetables and fresh fruits. This study is an attempt to analyze the value proposition of those organized supermarkets in the category of fresh fruits and vegetables segment in jayanagar. For analyzing the value proposition, following variables are identified and selected;

- Proximity

- Price

- Merchandise quality and mix (Including variety, depth, consistency etc)

- Store atmospherics

- Customer service

- Innovation or differentiation strategies in their offerings 


\subsection{Proximity}

Jayanagar is well developed residential area with the cosmopolitan setup. To cater to the different tastes and daily chores many organized supermarkets are entered in to this business. The partial lists of supermarkets formats in jayanagar are as follows :

- Namdhari Fresh,

- More

- Fresh @ Jayanagar

- Nilgiris

- Foodworld

- Spencer's

- DTH People Shoppe

- Reliance Fresh

- Safal Daily Fresh

- Subhiksha

Among the above supermarket formats, it was observed that majority of the supermarket does not concentrate on a in-depth \& full fledged green vegetables and fruits section except few retailers like Namdhari fresh, Reliance fresh, Safal daily fresh etc. hence, only above three supermarkets are considered for study purpose. It was observed that majority of population is still dependent on nearby fruits and vegetables market or other unorganized setup like push cart vendors for the purchase of fruits and green vegetables. Hence it is quite evident that supermarkets who concentrate on fresh green vegetables and fruits need to be located very near to the market. Therefore it is inferred that organized players with the business model of more green products need to establish high proximity to the market even though located in same locality.

\subsection{Price}

Bangalore is a cosmopolitan area with the diverse class of population across the different class of social setup. It was a general trend in the city population that consumer preferences towards these categories are ranked with the priority ranging from proximity or location, price and merchandise quality. Hence the value deliveries of these supermarkets were positioned accordingly. Due to various administrative reasons, these organized players were unable to add value in the area of proximity or location, but they are providing a value addition in terms of price substantially. It was observed that all these supermarkets were providing the value pricing in the area of fresh fruits and vegetables. This is due to the effort on fairly strong value chain and supply end network. For example Namdhari Fresh based out of Bangalore operates their own farm in the outskirts of Bangalore to provide fresh fruits and vegetables with better quality with the cost effective pricing. Similarly, Reliance Fresh appointed various agents for sourcing their fruits and vegetables from nearby farms. Hence these supermarket business models are dominant with value pricing. But ultimately, overall pricing of modern supermarket is not comparable with unorganized barring certain legal constraints.

\subsection{Merchandise quality and Mix}

Merchandise mix is central to the business model of any retail organization, these supermarkets have wide merchandise mix with various ranges in each category and sub categories. It was observed that Reliance Fresh Supermarket has more wide and deep merchandise mix catering to daily and specific needs of the customers. Merchandise quality also abserved to be more fresh and first grade quality with the high value proposition. Namdhari Fresh Supermarket also carries a medium merchandise width and depth as compared to an unorganized setup.

\subsection{Store Atmospherics}

Store atmospherics is the physical characteristics and surrounding influence of a retail store that is used to create an image in order to attract customers. This is an important element in organized retail inducing the shopping mood and 
mindset, which is more minute in nature and highly sensitive area also. The components of store atmospherics directly contributing to a store image, which ranging from exterior store atmosphere to interior store atmosphere.

\section{Exterior store atmosphere - Components \\ Parking facility \\ Store front \\ Display window \\ Place of business \\ Interior Store atmosphere - Components \\ Entrance \\ Store layout and traffic pattern \\ Aisles \\ Lighting \\ Product display \\ Shopping zone \\ Strategic placement of products \\ Point of purchase \\ Clean atmosphere}

It was observed that the supermarket which was taken for the study is maintaining a good atmosphere in both exterior and interior places. In exterior store locations these supermarkets allocated a adequate parking facility for two-wheeler's and public parking space opposite to store for four-wheelers etc. Reliance fresh store name and logo communicates a good brand image and their business model of green vegetables and fruits and value retailing. Place of supermarket is more strategic and provide convenience to their customers. Interior atmosphere of supermarket consists of wide entrance which can allow more traffic in to the stores with the seasonal product display at the entrance and other promotional offers displayed. Store layout is grid type with the more planned arrangement of selling space and walking space. In some supermarkets, merchandise display arrangements are complimentary in nature according to their target customers food habits and tastes. Majority of supermarkets plan their aisle space by selling bakery products with cakes and pastries. Vegetables and fruits product display and presentation are more attractive which reflects the freshness and quality of merchandise. All these supermarkets creates an shopping zone near to the freezer point where more innovative merchandise mix of vegetables and fruits are displayed, for instance value added packs of Reliance Fresh. Lighting arrangements are more customized according to the merchandise section in terms of brightness and intensity. Many of the dailies merchandise are strategically located in multiple shelves to avoid rushing in one shelf location. Points of purchase are planned very well which induce the impulse purchase on non-food items as well as daily chore items and chocolates etc. Overall store atmosphere is more conducing arising the mood of the shoppers with natural aroma. On the summary, overall store atmospherics directly contributes to the store image.

\subsection{Customer service and differentiation strategies}

Customer service of supermarket and daily products essentially covers the basic necessary services like availability of products, convenience, strategic display of products, store assistance and store timings etc. It was observed that supermarket who are in to the green vegetables and fruits business could not make the products available at the shelf on a continuous phase, due to administrative reasons like wastages and short shelf life period. Otherwise, these modern supermarkets were able to provide superior customer service in terms of store timings and other aspects.

Innovation or differentiation strategies are executed at different supermarket in different levels. It was observed that majority of the supermarket brought differentiation strategy only with respect to the merchandise mix or product display. But Reliance Fresh stores brought major breakthrough in the form 
of value added packs customized for the families where both husband and wife are employed. Value added merchandise mix of Reliance Fresh are as follows:

- Vegetables for sambar

- Vegetables for Fried rice

- Veg for Mexispicy CRN Salad

- Veg for Pulav/Biryani

- Yam slice

- Pumkin slice

- Caluliflower florets

- Cabbage shreds

- Carrot shreds

- Fruit mix

- Pineapple cleaned and wrapped

In addition to the merchandise mix, differentiation or innovation brought with the support technology in terms of Point of Sale speedy billing process, delivery methods, digital displays of price tags and other customer loyalty services etc.

\subsection{Findings and suggestions of the Study}

\subsection{Findings of the Study}

- Indian retail sector began its next journey from the early 2009 as market started reviving back.

- The recovery in consumer spending is visible across almost all the industry sectors especially in food and grocery.

- Consumers mindset has changed as affected by the global recession and learned the new wave of consumer speriding with more focus on value.

- It is mandatory for the retailers to revisit on their value and marketing strategies to map the customer's new mindset and their spending habits.
- One of the major challenges of these supermarkets is a lack of skill in well - oiled system of replenishment or back-ward integration.

- Providing value proposition in fruits and vegetables segment by these modern supermarkets are the key to their business model.

- Supermarket format essentially offer a service in terms of fast replenishment in daily staple goods and a bakery items on a continuous day-to-day basis.

- Indian shoppers are highly price sensitive in food shopping, therefore a format with wider choice and low prices will attract shoppers in this region.

- Modern formats of fruits and vegetables and their retail business model need to be realigned to cater to the local needs of Indian consumers.

- Modern retail formats dealing with fresh fruits and vegetables are not closely located to their customers.

- Modern supermarket dealing predominantly with fresh fruits and vegetables are strong in their local back end network, hence they were in a position to offer better value pricing to their customers. But overall they are not matching with local grocers.

- Reliance Fresh offers a wide and deep range of fruits and vegetables

- It was observed that modern supermarkets dealing primarily with green vegetables and fruits are carrying good quality and fresh merchandise.

- It was observed that the supermarket which was taken for the study is maintaining a good atmosphere in both exterior and interior places.

- Exterior display window and brand name \& logo were communicating the brand value. 
- Retail location is more strategic and provides convenience to their customers.

- Store layout and store traffic is designed according to their value in terms of merchandise classification.

- Point of purchase stimulating more impulse purchase among customers.

- Customer service with respect to the store assistance and technology driven service delivery like billing process, packaging and price tags makes the customer transaction efficient.

- Some of the retailers practicing differentiation strategy in overall business format in terms of merchandise and overall store experience is encouraging.

\subsection{Suggestions}

- Indian retail industry is more promising with tremendous opportunity for organized retail, hence Indian modern retail formats can expand their business with planned scaled activity with the support of appropriate business linkages both forward as well as backward direction.

- The demand for supermarket and convenience stores are very high, supermarkets need to capitalize on these opportunity with the strong back end supply network.

- Many modern formats can concentrate more on fresh fruits and vegetables as there are plenty of business space available in the market.

- Many supermarkets can enter into the deep business model of green vegetables and fruits to cater to their needs and lifestyle of the customers.

- Supermarkets can improve the quality of merchandise in terms of freshness and fast replenishment of green vegetables and fruits.
- Modern supermarkets need to source the green products directly from the farmers by establishing backward business linkages.

- Contract farming and customized cultivation of products through mutations- can add more value to the customers.

- Value chain initiatives need to be practiced right from farmer level to customer shelf, in order to support these values, modern outlets can expand their business backward or outsource to professional bodies in the areas of farming, aggregating, transporting, storing and replenishment activities.

- Modern supermarket need to increase their proximity to their market on the basis of the number of households.

- Modern supermarkets need to offer wider range merchandise in the area of green vegetables and fruits except few players.

- Store atmosphere and layout can be improved according to their business value or theme.

- Unique mutation varieties can be introduced in both fruits and vegetables to provide superior value to the customers.

\subsection{Business Model and strategic framework summary}

After analyzing various factors which contributes to the value delivery, a theoretical framework has been designed for supermarket which is termed as Supermarket business model. The models of the same are as follows:

This business model essentially starts from purpose of the business and further describes about supermarkets strategy of establishing proximity with appropriate administrative network with source, buyers and logistics service providers. Value pricing can be exercised if a supermarket establish strong supply chain network with appropriate business linkages, the same network can be scaled to bring 
the better merchandise choice and align customer service with the appropriate customer service network. All these leads to better store image and hence to business development.

Fig. 4.2. Value proposition Model for supermarkets

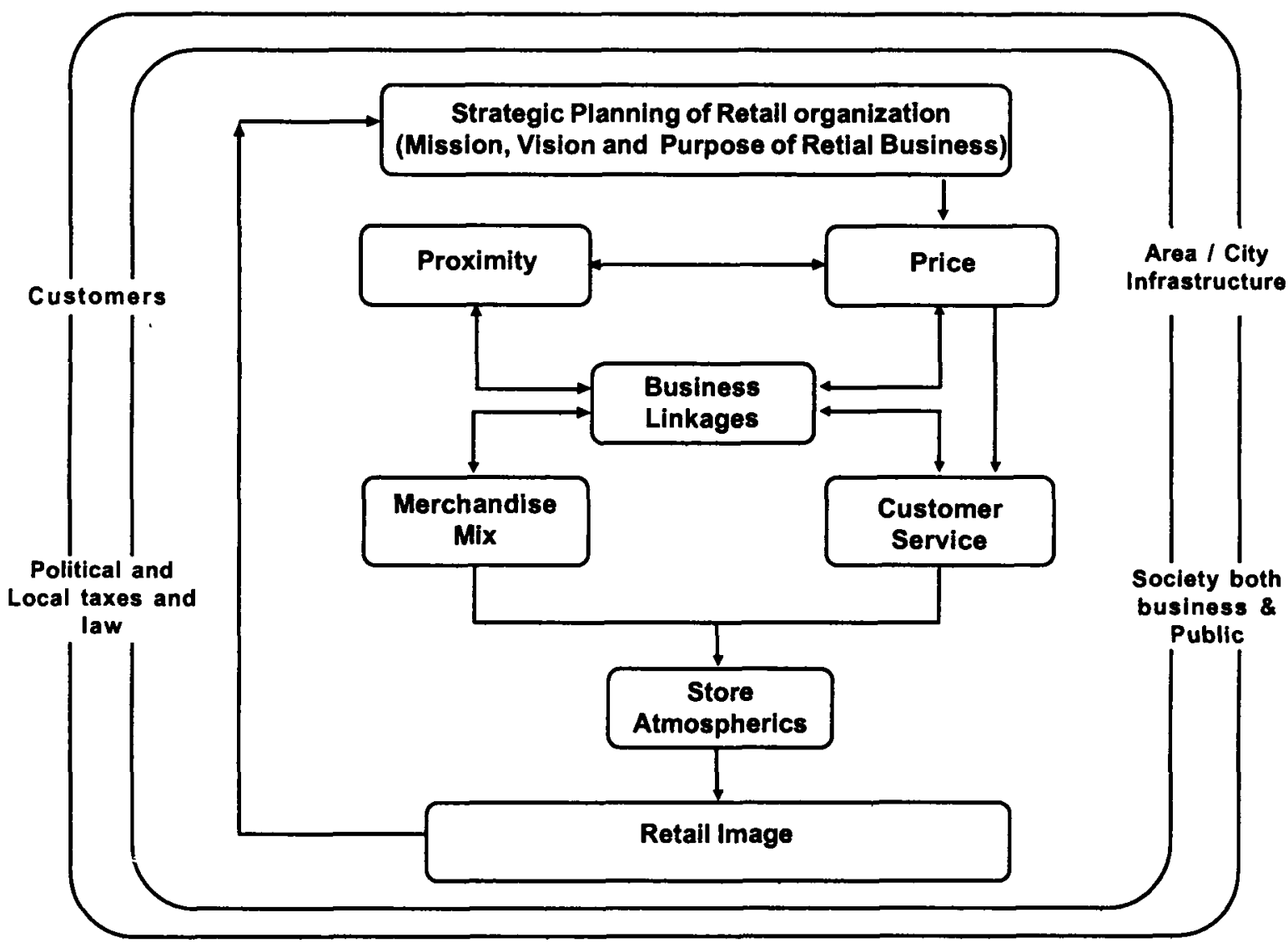

\section{REFERENCES}

1. wuw-03.ibm.com/industries/

consumerproducts/doc/content/bin/

CCRRCA_- Format_Success_Study.pdf, accessed on 28th may 2009.

2. Tripathi Sanjeev, Sinha.P.K, (2008),

“Choiceof Retail store and retail store format: A

Hierarchical logit model" working paper series-2008-04-03, Indian institute of Management, Ahmadabad.
3. Sinha Piyush Kumar, Kar Sanjay Kumar (2007), "An insight into the growth of New retail formats in India", Working paper series - 2007-03-04- Indian Institute of Management, Ahmadabad.

4. Sinha Piyush Kumar; Mathew Elizabeth; Kansal Ankur; (2005), "Format choice of food and grocery retailers"; Working paper series - 2005-07-04; Indian institute of Management,Ahmadabad. 
5. International food policy research institute; (2008), "The rise of supermarkets and their development implications - International experience relevant for India", IFPRI Discussion paper 00752; http:// unw.ifpri.org/pubs/dp/ifpridp00752.pdf, accessed on 22nd Feb 2009.

6. http://www.cbreindia.com/india/eng/ document/Market Reports/ india\%20retail\%20market\%20 view\% $20-\% 20$ july\%202008.pdf, accessed on 13th March 2009.

7. Atmosphere", Shari waters, http:// retail.about.com/od/glossary/g/ atmosphere.htm, accessed on 9th June 2009.

8. "Products", http://www.namdharifresh.com/, accessed on 22nd May 2009.
9. http://uww.asklaila.com/search/Bangalore/ Jaya\%20nagar\%204th\%20block/ supermarkets/?searchNearby=false, accessed on 26th May 2009.

10. "Fresh and small", http:// uww.businessworld.in/index.php/Freshand-Small.html, accessed on 23rd May 2009.

11. Evans, berman, Strategic retail management, 10th edition, Pearson education, New Delhi(2008)

12. Singhal Aravind, "Re-connecting with the consumer", Business Standard, $30^{\text {th }}$ July 2009. 